\title{
A case of pancreatic metastasis arising from occult lung cancer
}

\author{
Ryo Kodama*1, Hisanobu Saegusa ${ }^{1}$, Hiroyasu Ushimaru ${ }^{1}$, Mutsuki Makino ${ }^{2}$, Kenji Kawaguchi ${ }^{2}$ \\ ${ }^{1}$ Department of Gastroenterology, Shinonoi General Hospital, Nagano, Japan \\ ${ }^{2}$ Department of Pathology, Shinonoi General Hospital, Nagano, Japan
}

Received: February 6, 2018

Accepted: April 16, 2018

Online Published: April 20, 2018

DOI: $10.5430 /$ crim.v5n2p21

URL: https://doi.org/10.5430/crim.v5n2p21

\begin{abstract}
A 57-year-old man was admitted with complaints of stiffness on the right clavicle. Imaging study revealed swelling of multiple lymph nodes and pancreatic mass, but there were no such findings in the lung. Endoscopic ultrasound-guided fine needle aspiration for mediastinum lymph node and pancreatic mass revealed a poorly differentiated adenocarcinoma. He was diagnosed of pancreatic cancer with multiple lymph node metastases. Chemoradiotherapy was conducted. Six months later, he suffered from cardiac tamponade and died. The autopsy revealed a small nodule of poorly differentiated adenocarcinoma in the lung that could not be pointed out by computed tomography. Immunohistochemistry showed that both tumors of the lung and pancreas were positive for thyroid transcription factor-1 and napsin A, which are specific markers of lung cancer. Final diagnosis was primary lung cancer with metastases to the pancreas and heart. Pancreatic metastasis from occult lung cancer is rare. Lung cancer must be suspected when carcinoma of unknown primary is detected, even in the absence of the image findings of the lung. Immunostaining is useful in determining the primary site; hence, obtaining the cancer tissue is important.
\end{abstract}

Key Words: Carcinoma of unknown primary, Pancreatic cancer, Cancerous pericarditis, Cardiac tamponade, Occult lung cancer, Immunohistochemistry

\section{INTRODUCTION}

Recently, various anticancer agents have been developed, and the prognosis of cancer is expected to improve with appropriate treatment; therefore, the detection of the primary site is important. Carcinoma of unknown primary is not frequently encountered; it constitutes 3\%-5\% of all human malignancies. $^{[1-3]}$ Among carcinoma of unknown primary, pancreas, biliary tree, and lung are major parts of the origin, which is pathologically diagnosed at autopsy. ${ }^{[4]}$ Occult lung cancer with multiple metastases is not rare; however, pancreatic metastasis arising from lung cancer is rare. This is the first case report of occult lung cancer with pancreatic metastasis.

\section{CASe PResentation}

A 57-year-old Japanese man presented with stiffness on the right clavicle. His medical history included duodenal ulcer and ureteral stone. He smoked 20 cigarettes per day for 30 years. He did not drink alcohol. Physical examination revealed an elastic, hard lymph node swelling, of the size of a chicken egg, on the right clavicle. There were no significant findings on the chest or abdomen. Laboratory data (complete blood count, chemistry, urinalysis, and tumor markers) implied an inflammatory condition (white blood cell count, $11,500 / \mathrm{mm}^{3}$; C-reactive protein, $\left.1.08 \mathrm{mg} / \mathrm{dl}\right)$. Some tumor markers were elevated (carcinoembryonic antigen,

\footnotetext{
*Correspondence: Ryo Kodama, PhD; Email: kodryo@grn.janis.or.jp; Address: Department of Gastroenterology, Shinonoi General Hospital, Nagano, Japan
} 
$97.0 \mathrm{ng} / \mathrm{ml}$; carbohydrate antigen $19-9,161.0 \mathrm{U} / \mathrm{ml}$; squamous cell carcinoma, $21.9 \mathrm{ng} / \mathrm{ml}$ ). Thoracoabdominal computed tomography (CT) scan showed prominent, multiple lymphadenopathies that were thought to be metastases from both above and below the clavicle and mediastinum. There was no abnormal finding on radiologic imaging of the lung. In the pancreatic body, there was a $15-\mathrm{mm}$ lesion that was slightly more enhanced than the normal surrounding pancreas in the delayed phase (see Figure 1). Magnetic resonance cholangiopancreatography showed stenosis of the main pancreatic duct in the pancreatic body (see Figure 2a). Positron emission tomography revealed fluorodeoxyglucose accumulation in the neck, axilla, mediastinum, and pancreatic body but none in the lungs (see Figure 2b). Endoscopic ultrasoundguided fine needle aspiration (EUS-FNA) of a mediastinal lymph node (see Figure 3a) and the pancreatic mass (see Figure $3 b$ ) was performed. The histology of both specimens revealed poorly differentiated adenocarcinoma (see Figure 3c). Although the cervical and mediastinal lymphadenopathies were more dominant than the peritoneal lymphadenopathies, no primary lesion could be detected anywhere in the body, except in the pancreas. Therefore, a diagnosis of pancreatic cancer with multiple lymph node metastases was done. The opinion of pathologists was same idea about this patient's diagnosis. Chemotherapy with gemcitabine/S-1 and radiotherapy for the cervical lymphadenopathies were performed. After five months, the patient developed shortness of breath. CT scan revealed hydrothorax and retention of pericardial fluid (see Figure 4a) with cardiac tamponade. Pericardiocentesis was performed (see Figure 4b), and the cytology of the pericardial fluid revealed poorly differentiated adenocarcinoma. With a diagnosis of cancerous pericarditis, pericardial drainage and injection of bleomycin into the pericardial cavity were performed. Six months after the start of chemoradiotherapy, or 18 days after the diagnosis of cardiac tamponade, the patient died. On autopsy, a 7-mm nodule was detected in the pancreatic body and was shown as a poorly differentiated adenocarcinoma (see Figure 5). Similarly, an examination of the pericardium showed a poorly differentiated adenocarcinoma (see Figure 6). In the apex of the left lung, a small nodule was noted and analyzed by histology as a poorly differentiated adenocarcinoma (see Figure 7). Both tissues from the lung and pancreatic lesions were positive for thyroid transcription factor-1 (TTF-1) and napsin A (see Figure 8). After the completion of autopsy, the final diagnosis was primary lung cancer with metastases to the pancreas, lymph nodes, and heart.

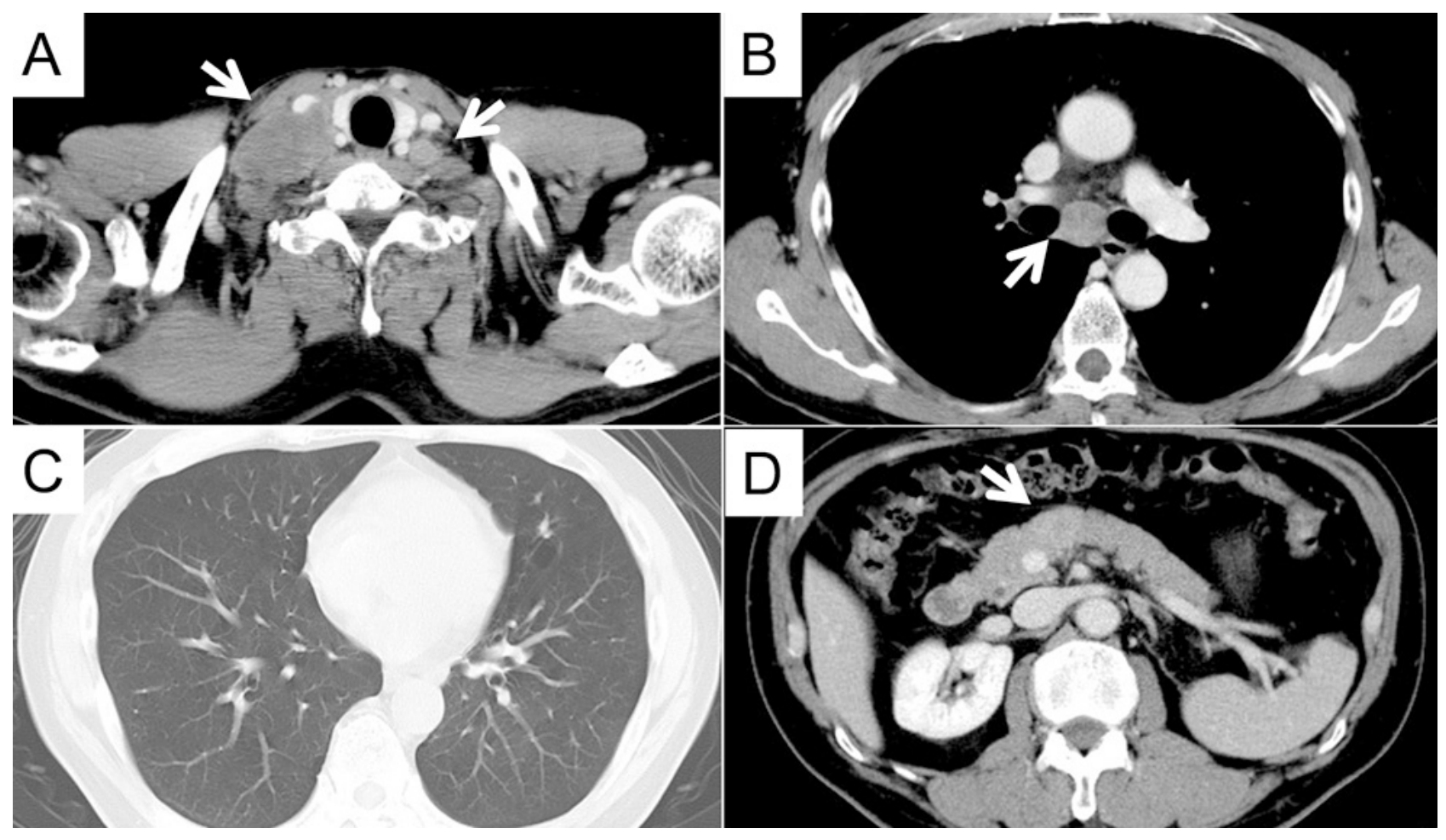

Figure 1. CT scan on admission

$C T$ scan revealed extensive, multiple lymphadenopathies above and below the clavicle (A, arrow), and in the mediastinum (B, arrow). There was no abnormal finding in the lungs $(C)$. In the pancreatic body, there is a 15-mm lesion that was slightly more enhanced than the normal surrounding pancreas in the delayed phase ( $D$, arrow). 

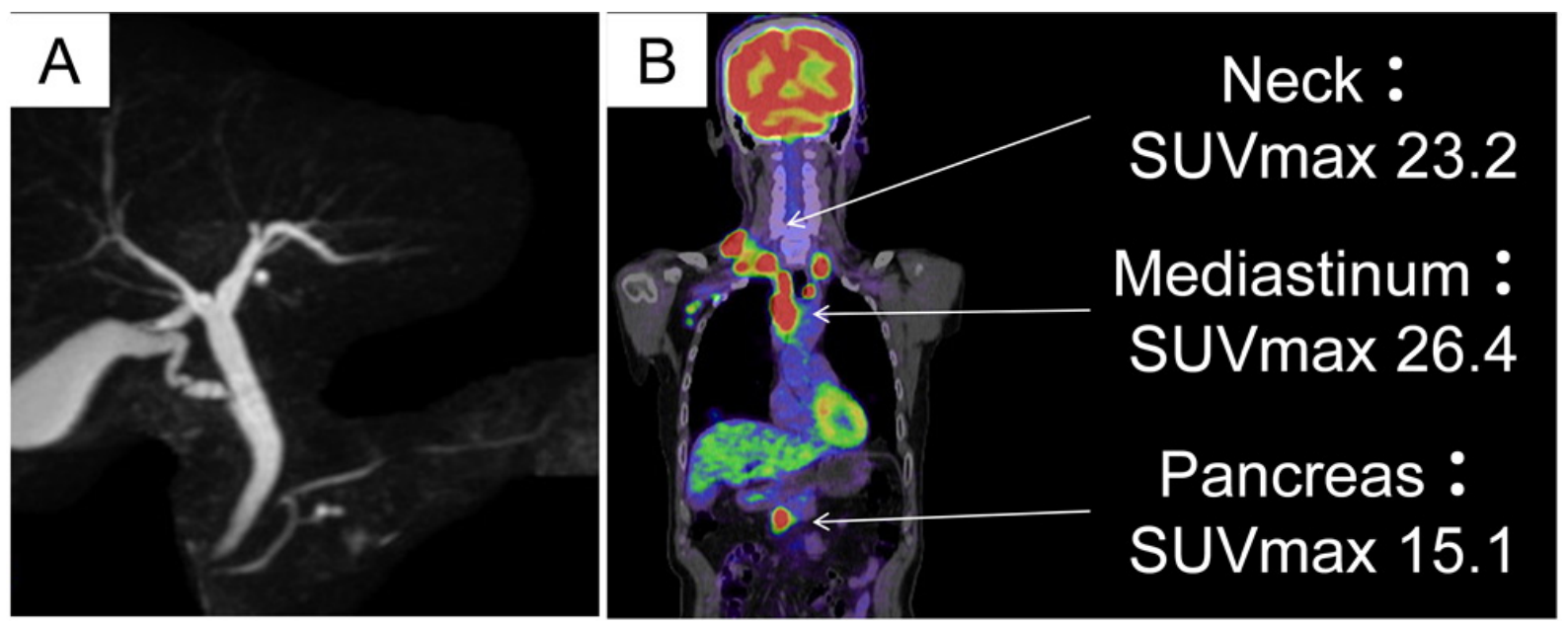

Figure 2. MRCP and PET on admission

MRCP examination shows stenosis of the main pancreatic duct within the pancreatic body (A). Positron emission tomography (B) revealed fluorodeoxyglucose accumulation in the neck, axilla, mediastinum, and pancreatic body. There was no accumulation in the lungs.
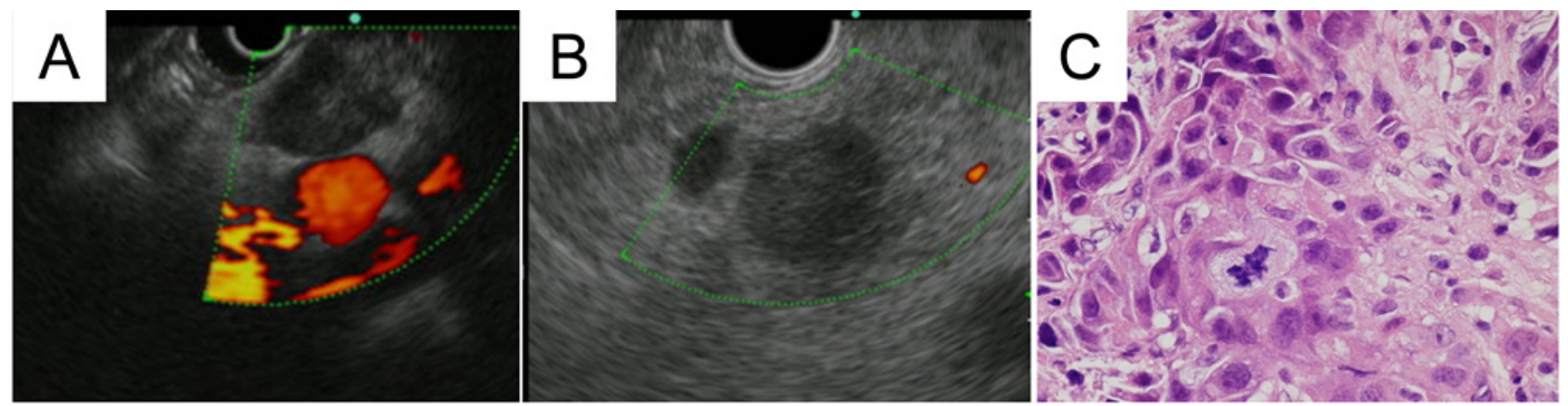

Figure 3. Endoscopic ultrasound-guided fine needle aspiration

Endoscopic ultrasound-guided fine needle aspiration of a mediastinal lymph node (A) and the pancreatic mass (B) were done. Histology of both specimens revealed poorly differentiated adenocarcinoma $(C)$ (Hematoxylin \& Eosin, $\times 400)$.

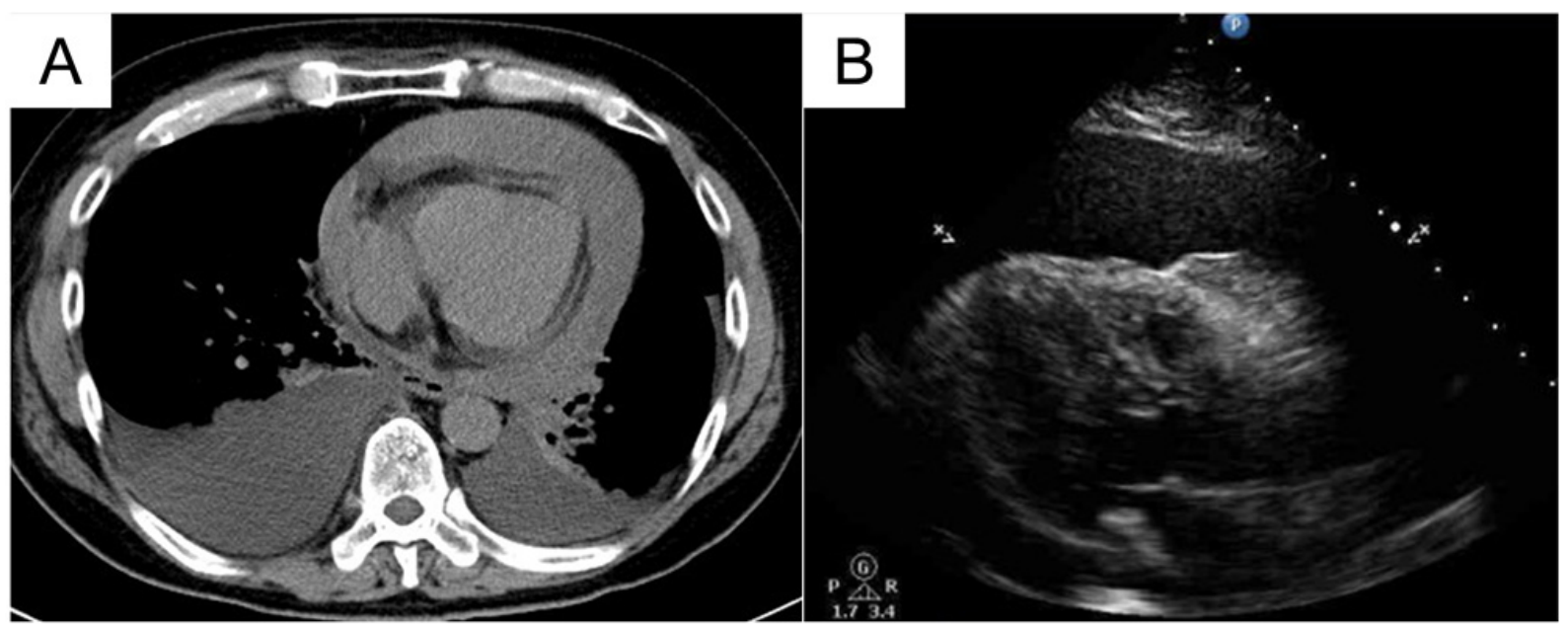

Figure 4. CT scan and echocardiography at five months after starting chemo-radiotherapy CT scan reveals hydrothorax and retention of pericardial fluid (A). Pericardiocentesis was done to manage the cardiac tamponade (B). 

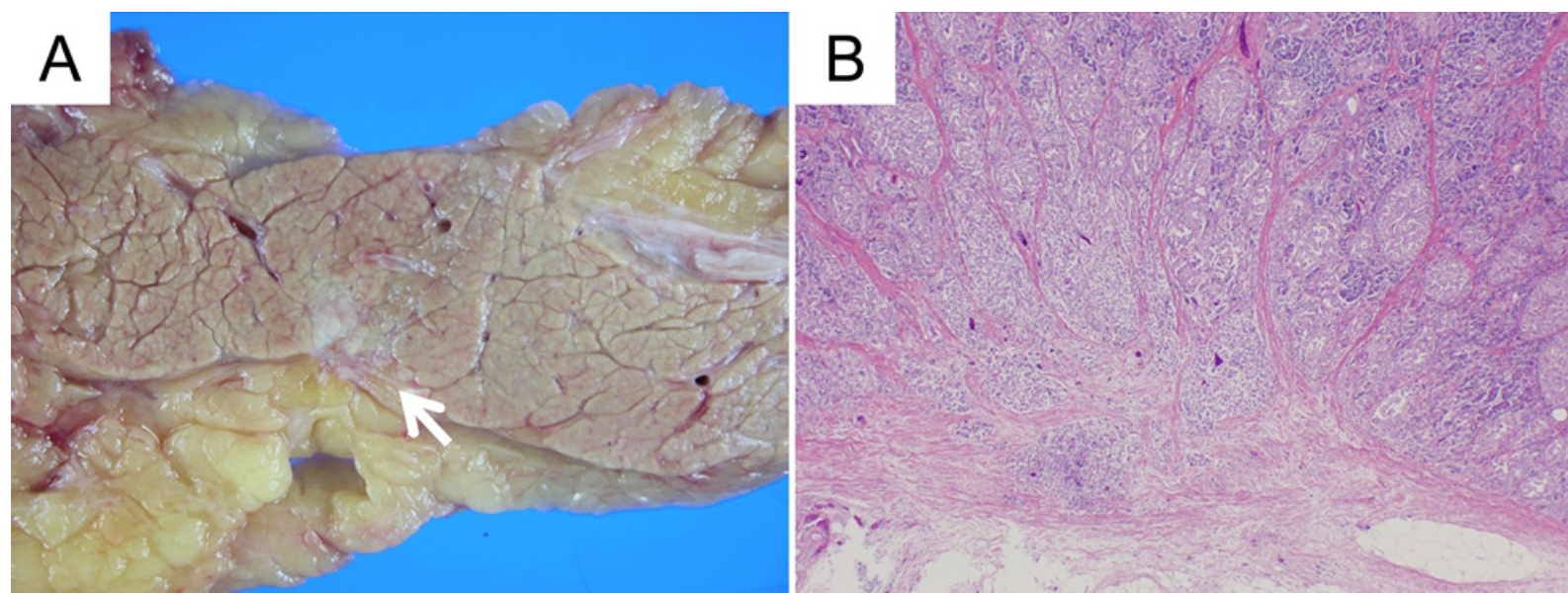

Figure 5. The autopsy findings on the pancreas

Grossly, there is a 7-mm nodule in the pancreatic body (A, arrow). Pathology examination showed poorly differentiated adenocarcinoma invading the pancreas $(B)$ (Hematoxylin \& Eosin, $\times 40)$.
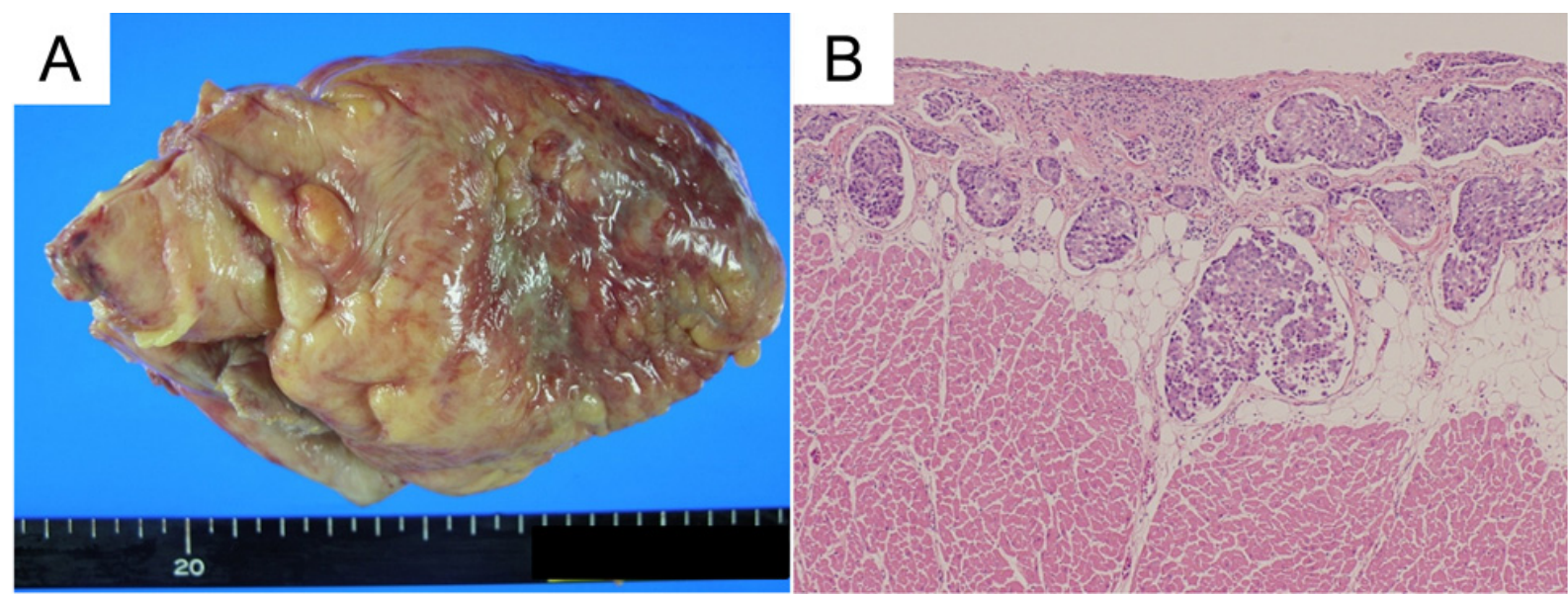

Figure 6. The autopsy findings on the heart

The autopsy findings on the heart (A). Pathology examination showed poorly differentiated adenocarcinoma invading the pericardia $(B)$ (Hematoxylin \& Eosin, $\times 100)$.
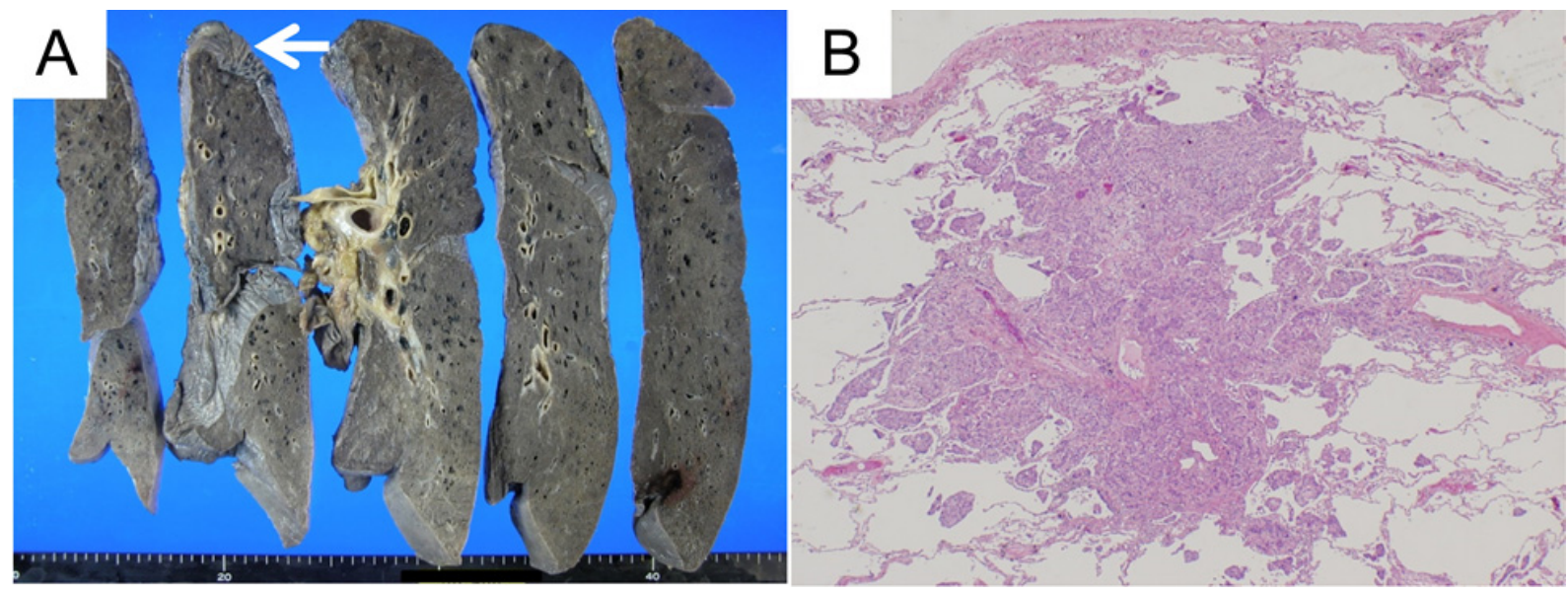

Figure 7. The autopsy findings on the lung

The autopsy revealed a small nodule in the apex of the left lung (A, arrow). Pathology examination of this nodule showed poorly differentiated adenocarcinoma $(B)$ (Hematoxylin \& Eosin, $\times 40)$. 

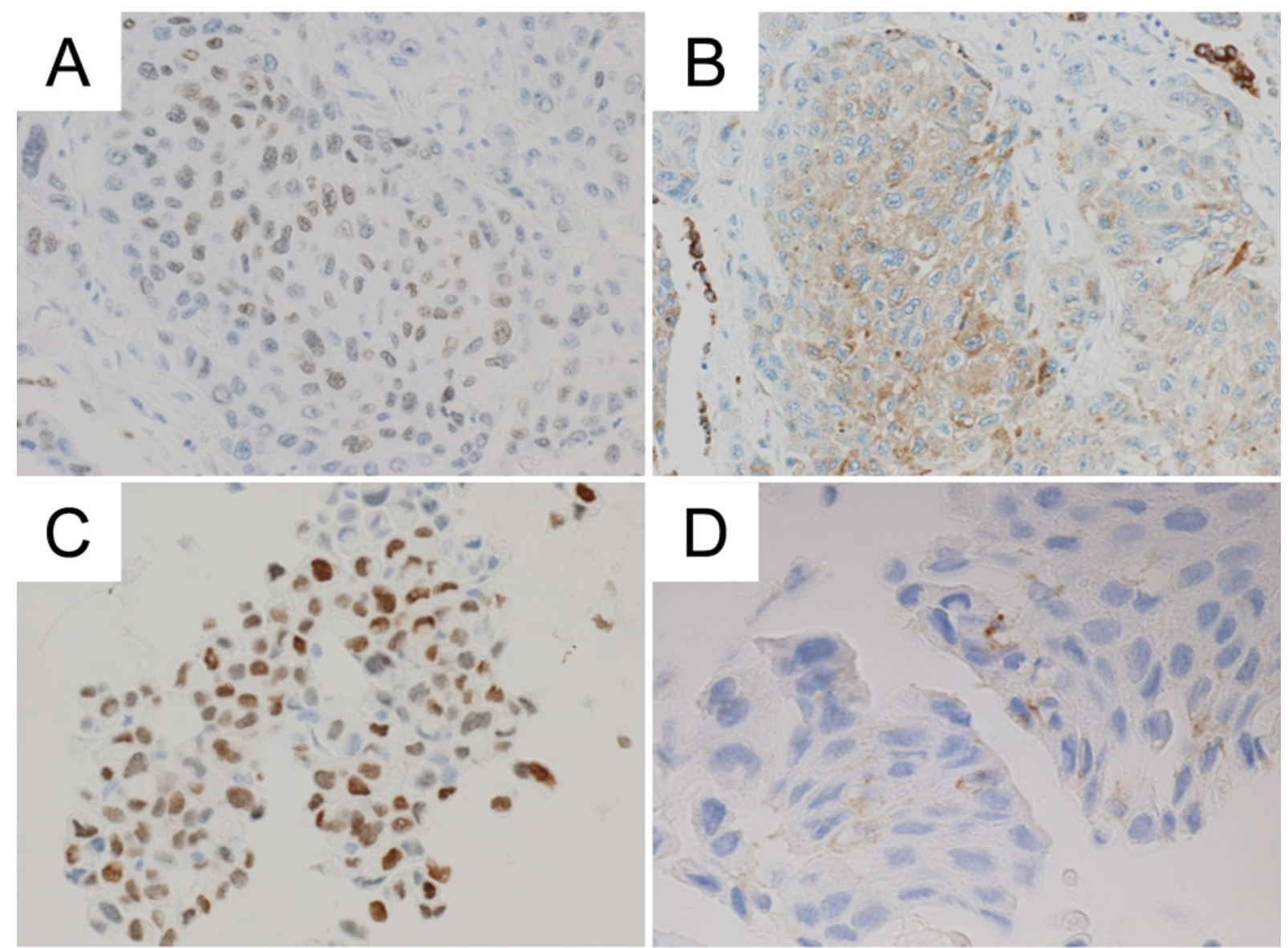

Figure 8. Immunohistochemistry of the tissues from the lung and pancreas

Immunohistochemistry shows that the lung nodule is positive for TTF-1 (A) and napsin A (B). The tumor in the pancreas is also positive for TTF-1 (C) and napsin A (D) ( $\times 400)$.

\section{Discussion}

Carcinoma of unknown primary is a rare disease, and it is difficult to detect the primary site; however, primary site detection is important because various anticancer agents have been developed in recent years, and cancer prognosis is expected to improve with appropriate treatment. Pancreatic cancer is common; however, the pancreatic mass may be a secondary tumor from other cancer. Adsay et al. reported that on pathologic examination of 4,955 adult autopsy cases, pancreatic metastasis was seen in 190 cases (3.8\%), and 81 $(1.6 \%)$ of these were secondary tumors, most commonly from the lungs (34 cases, 0.7\%). ${ }^{[5]}$ Imaging findings of metastatic pancreatic tumors reflect the primary tumor character; therefore, metastatic pancreatic tumors have no typical radiologic findings. Swensen et al. reported that it was not possible to radiologically differentiate between pancreatic primary and secondary lesions. ${ }^{[6]}$ Some metastatic pancreatic cancer cases may be diagnosed and treated as primary pancreatic cancer. In our case, a massive lymphatic involvement was seen, especially in the lymph nodes of the neck and mediastinum; these findings are unusual in pancreatic cancer. If we would have suspected metastatic pancreatic cancer and consulted with the pathologist, lung cancer diagnosis may have been possible.

Immunostaining is a useful tool to pathologically detect primary lesion. TTF-1 and napsin A are specific markers for lung cancer. TTF- 1 is a transcription factor that plays a role in the development and physiology of the thyroid and lungs. In the thyroid, TTF-1 is expressed in follicular and parafollicular cells. In the lung, TTF-1 is thought to play a role in the regulation of surfactant $\mathrm{B}$ production. In lung carcinomas, TTF-1 expression has been reported to be positive in almost all small cell carcinomas, in majority of adenocarcinomas, and non-mucinous bronchio-alveolar carcinomas. Among non-pulmonary and non-thyroid primary tumors, only small types of carcinomas, namely, bladder $(5.1 \%)$, prostate $(1.2 \%)$, stomach $(0.9 \%)$, salivary gland $(1.8 \%)$, and colon $(2.5 \%)$ carcinomas, were TTF-1 positive. TTF-1 has been used as a reliable marker to distinguish between primary and metastatic lung tumors, especially when dealing with adenocarcinoma, 
because the lung is one of the most common sites of cancer metastasis. ${ }^{[7]}$ However, napsin A, a relatively new marker, is an aspartic protease that is present on the epithelial cells of the lungs and kidney. Napsin A had $83 \%$ sensitivity and $98 \%$ specificity to lung adenocarcinoma and has recently been shown to be more sensitive and specific than TTF-1. ${ }^{[8]}$ However, it should be noted that napsin A is frequently expressed in renal cell carcinomas, especially the papillary and clear cell subtypes. ${ }^{[9]}$ Justin et al. reported that of the 31 pancreatic cancers, none were positive for TTF-1 and napsin A. ${ }^{[10]}$

Immunostaining is useful for discriminating between pancreatic cancer and lung cancer; therefore, obtaining tissue samples is important. EUS-FNA makes it easy to obtain pancreatic tissue samples. EUS-FNA for metastatic pancreatic cancer was reported to have sensitivity and specificity of $80 \%-93.8 \%$ and $60 \%-100 \%$, respectively. ${ }^{[1-13]}$ EUSFNA with the histology of the specimens is thought to be a sensitive and accurate method for the definitive metastatic disease diagnosis. In our case, EUS-FNA was useful in obtaining pancreatic tissue; however, it is enlightening that to exactly diagnose, we need to think about the possibility that the pancreatic mass is a metastatic tumor and perform immunostaining. This is the first case report of the metastatic pancreatic cancer from occult lung cancer. Although our case is very rare, when we encounter another case of atypical pancreatic cancer, we have to distinguish it from metastatic cancer, obtain tissue, and confirm the immunostaining of the tissue, even if the primary lesion is not detected.

\section{Conclusion}

In conclusion, we reported a rare case of autopsy-diagnosed occult lung cancer that was initially treated as pancreatic cancer with cancerous pericarditis and cardiac tamponade.
In a patient diagnosed with pancreatic cancer with multiple metastases with atypical signs, we underscored the importance of discriminating whether the malignancy is primary or metastatic.

\section{ABbREVIATIONS}

CT: Computed tomography; MRCP: Magnetic resonance cholangiopancreatography; EUS-FNA: Endoscopic ultrasound-guided fine needle aspiration; TTF-1: Thyroid transcription factor-1

\section{AVailability OF DATA AND MATERIALS}

Data sharing is not applicable to this article as no datasets were generated or analyzed during the current study.

\section{Authors' CONTRIBUtions}

RK was the major contributor in writing the manuscript. HS and HU helped revise the manuscript. MM and KK performed the histopathological examination. All authors read and approved the final manuscript.

\section{Consent}

Written informed consent was obtained from the patient for publication of this case report and any accompanying images. A copy of the written consent is available for review by the Editor-in-Chief of this journal.

\section{ACKNOWLEDGEMENTS}

The authors would like to thank Enago (www . enago.jp) for the English language review. The authors also thank Satoru Joshita as a special adviser.

\section{CONFlicts OF INTEREST Disclosure}

The authors declare that they have no competing interests.

\section{REFERENCES}

[1] van de Wouw AJ, Janssen-Heijnen ML, Coebergh JW, et al. Epidemiology of unknown primary tumours; incidence and population-based survival of 1285 patients in Southeast Netherlands, 1984-1992. Eur J Cancer. 2002; 38: 409-413. https://doi .org/10.1016/S095 9-8049(01) 00378-1

[2] Randén M, Rutqvist LE, Johansson H. Cancer patients without a known primary: incidence and survival trends in Sweden 19602007. Acta Oncol. 2009; 48: 915-920. PMid:19363713. https: //doi.org/10.1080/02841860902862503

[3] Pavlidis N, Fizazi K. Carcinoma of unknown primary (CUP). Crit Rev Oncol Hematol. 2009; 69: 271-278. PMid:18977667. https: //doi.org/10.1016/j.critrevonc.2008.09.005

[4] Mayordomo JI, Guerra JM, Guijarro C, et al. Neoplasms of unknown primary site: a clinicopathological study of autopsied patients. Tu- mori. 1993; 79: 321-4. PMid:8116074.

[5] Adsay NV, Andea A, Basturk O, et al. Secondary tumors of the pancreas: an analysis of a surgical and autopsy database and review of the literature. Virchows Arch. 2004; 444: 527-535. PMid:15057558. https://doi.org/10.1007/s00428-004-0987-3

[6] Swensen T, Osnes M, Serck-Hanssen A. Endoscopic retrograde cholangio-pancreatography in primary and secondary tumours of the pancreas. Br J Radiol. 1980; 53: 760-4. PMid:7437685. https: //doi .org/10.1259/0007-1285-53-632-760

[7] Matoso A, Singh K, Jacob R, et al. Comparison of thyroid transcription factor - 1 expression by 2 monoclonal antibodies in pulmonary and nonpulmonary tumors. Appl Immunohistochem Mol Morphol 2010; 18: 142-149. PMid:19887917. https://doi.org/10.109 7/PAI. 0b013e3181bdf4e7

[8] Whithaus K, Fukuoka J, Prihoda TJ, et al. Evaluation of napsin 
A, cytokeratin 5/6, p63, and thyroid transcription factor 1 in adenocarcinoma versus squamous cell carcinoma of the lung. Arch Pathol Lab Med. 2012; 136: 155-62. PMid:22288962. https: //doi.org/10.5858/arpa.2011-0232-0A

[9] Ordó-ez NG. Napsin A expression in lung and kidney neoplasia: a review and update. Adv Anat Pathol. 2012; 19: 66-73. PMid:22156835. https://doi.org/10.1097/PAP.0b013e31823e472e

[10] Bishop JA, Sharma R, Illei PB. Napsin A and thyroid transcription factor-1 expression in carcinomas of the lung, breast, pancreas, colon, kidney, thyroid, and malignant mesothelioma. Hum Pathol. 2010; 41: 20-25. PMid:19740516. https://doi.org/10.1016/j.humpat h. 2009.06.014

[11] Ardengh JC, Lopes CV, Kemp R, et al. Accuracy of endoscopic ultrasound-guided fine-needle aspiration in the suspicion of pancreatic Inetastases. BMC Gastroenterol. 2013; 13: 63. PMid:23578194. https://doi.org/10.1186/1471-230X-13-63

[12] Krishna SG, Bhattacharya A, Ross WA, et al. Pretest prediction and diagnosis of metastatic lesions to the pancreas by endoscopic ultrasound-guided fine needle aspiration. J Gastroenterol Hepatol. 2015; 30: 1552-1560. PMid:25867963. https://doi.org/10.1 $111 /$ jgh. 12973

[13] Fabbri C, Luigiano C, Maimone A, et al. Endoscopic ultrasoundguided fine-needle biopsy of small solid pancreatic lesions using a 22-gauge needle with side fenestration. Surg Endosc. 2015; 29: 1586-1590. PMid:25303907. https://doi.org/10.1007/s004 64-014-3846-6 